\title{
Glycine-alanine dipeptide repeats spread rapidly in a repeat length- and age- dependent manner in the fly brain
}

\author{
Javier Morón-Oset ${ }^{1}$, Tessa Supèr ${ }^{1}$, Jacqueline Esser ${ }^{1}$, Adrian M. Isaacs ${ }^{2}$, Sebastian Grönke ${ }^{1}$ and Linda Partridge ${ }^{1,3^{*}}$
}

\begin{abstract}
Hexanucleotide repeat expansions of variable size in C9orf72 are the most prevalent genetic cause of amyotrophic lateral sclerosis and frontotemporal dementia. Sense and antisense transcripts of the expansions are translated by repeat-associated non-AUG translation into five dipeptide repeat proteins (DPRs). Of these, the polyGR, polyPR and, to a lesser extent, polyGA DPRs are neurotoxic, with polyGA the most abundantly detected DPR in patient tissue. Trans-cellular transmission of protein aggregates has recently emerged as a major driver of toxicity in various neurodegenerative diseases. In vitro evidence suggests that the C9 DPRs can spread. However, whether this phenomenon occurs under more complex in vivo conditions remains unexplored. Here, we used the adult fly brain to investigate whether the C9 DPRs can spread in vivo upon expression in a subset of neurons. We found that only polyGA can progressively spread throughout the brain, which accumulates in the shape of aggregate-like puncta inside recipient cells. Interestingly, GA transmission occurred as early as 3 days after expression induction. By comparing the spread of 36, 100 and 200 polyGA repeats, we found that polyGA spread is enhanced upon expression of longer GA DPRs. Transmission of polyGA is greater in older flies, indicating that age-associated factors exacerbate the spread. These data highlight a unique propensity of polyGA to spread throughout the brain, which could contribute to the greater abundance of polyGA in patient tissue. In addition, we present a model of early GA transmission that is suitable for genetic screens to identify mechanisms of spread and its consequences in vivo.
\end{abstract}

Keywords: C9orf72, Dipeptide repeat proteins, PolyGA, Drosophila, Spread, Repeat size, Ageing

\section{Introduction}

Frontotemporal Dementia (FTD) and Amyotrophic Lateral Sclerosis (ALS) are devastating and currently intractable neurodegenerative diseases, characterized histologically by the progressive loss of neurons in the frontal and temporal lobes, or upper and lower motor neurons, respectively [1]. Patients with either disease show a time-dependent progression of symptoms, yet the causes of this deterioration remain unknown.

An expansion of the hexanucleotide sequence GGGGCC in the C9orf72 (C9) gene, ranging from 30 to several thousand repeats, is the most common familial cause for both

\footnotetext{
* Correspondence: partridge@age.mpg.de

${ }^{1}$ Max Planck Institute for Biology of Ageing, Joseph-Stelzmann-Strasse 9b, 50931 Cologne, Germany

${ }^{3}$ Department of Genetics, Evolution and Environment, Institute of Healthy Ageing, University College London, Darwin Building, Gower Street, London WC1E 6BT, UK

Full list of author information is available at the end of the article
}

FTD and ALS [2-4]. The hexanucleotide expansion is transcribed in both sense and antisense directions, and gives rise to hexanucleotide repeat RNA that accumulates in intranuclear and extranuclear RNA foci $[2,4-6]$. In addition, the repeat RNAs can be translated in both directions in all reading frames, by repeat-associated non-AUG (RAN) translation, into 5 different dipeptide repeat (DPR) proteins: polyGA, polyGP, polyGR, polyPA and polyPR [79]. Numerous studies have addressed the differential toxicity of C9 RNA foci and DPRs, and have largely concluded that DPRs exert greater toxicity, especially the arginine-rich DPRs and, to a lesser extent, polyGA [10, 11]. However, the relative toxicity of the five DPRs has been mostly deduced from experimental production of proteins with much lower numbers of repeats than those seen in human patients, due to the difficulties in cloning repeat constructs. Importantly, the repeat length of proteins involved in other

(c) The Author(s). 2019 Open Access This article is distributed under the terms of the Creative Commons Attribution 4.0 International License (http://creativecommons.org/licenses/by/4.0/), which permits unrestricted use, distribution, and 
neurodegenerative diseases, such as huntingtin and ataxin3 , greatly influences their toxicity [12].

Although the arginine containing DPRs have so far proved the most toxic in animal and cellular models, in patients the contribution of different DPRs to overall toxicity is likely to be affected by their abundance. GA aggregates are the most abundantly detected DPR in patient tissues $[8,13]$, and it is therefore important to understand the behaviour of this protein at different lengths.

An emerging theme in the field of neurodegenerative diseases is that specific toxic proteins can spread transcellularly, thus contributing to the clinical progression shown by patients [14]. For instance, in experimental models, TDP-43, which typically aggregates in ALS and FTD [1], can spread trans-neuronally in cells [15] and mice [16]. Similarly, three independent studies have reported transmission of the C9 DPRs in cell culture models [17-19]. However, whether this phenomenon occurs in vivo remains unexplored.

We have investigated whether the C9 DPRs spread in vivo. We used the powerful genetics of Drosophila and found that, out of the three toxicity-associated DPRs, only GA DPRs spread in vivo in the fly brain, which accumulate in recipient cells as intracellular aggregate-like puncta. Furthermore, spreading was dependent on the repeat length of the GA DPRs, and their transmission was greater in the brains of older flies.

\section{Materials and methods}

\section{Drosophila stocks and maintenance}

Fly stocks were kept at $65 \%$ humidity on a 12:12 h light: dark cycle and fed a standard sugar/yeast/agar (SYA) diet [20]. For experiments using the pan-neuronal elavGS driver, experimental flies developed and were allowed to mate for 2 days at $25^{\circ} \mathrm{C}$, after which female flies were sorted to SYA food with $200 \mu \mathrm{M}$ RU486 (Mifepristone) at a density of 20 flies/vial and maintained at $25^{\circ} \mathrm{C}$ for 3 days. Flies used for propagation experiments expressed the temperature-sensitive Gal4 inhibitor $\mathrm{Gal}_{80}{ }^{\mathrm{ts}}$ to minimize the expression of the UAS transgenes during development. This inhibitor is active at $18{ }^{\circ} \mathrm{C}$ and can be inhibited to derepress Gal4 activity by shifting flies to $29^{\circ} \mathrm{C}$ [21]. Therefore, flies used for propagation experiments developed and were allowed to mate for 2 days at $18{ }^{\circ} \mathrm{C}$, after which female flies were sorted into SYA food at a fly density of 20 flies/vial and maintained at $18{ }^{\circ} \mathrm{C}$ or $29^{\circ} \mathrm{C}$ as indicated for each experiment.

The following transgenic fly lines were obtained from the Bloomington Drosophila Stock Center: tubulinGal80 $^{\text {ts }}$ (BDSC_7019), orco-Gal4 (BDSC_23292), R9D03Gal4 (BDSC_40726; hereafter referred to as OL-Gal4), UAS-eGFP.NLS (BDSC_4776) and UAS-syt.eGFP
(BDSC_6926). The elav-GS driver line was obtained as a generous gift from Dr. Hervé Tricoire (CNRS, France) [22]. The rest of the fly lines used were generated for this study.

\section{Generation of transgenic fly lines and genetics}

To generate the mCherry-tagged DPR constructs, we first PCR amplified mCherry using the Phusion polymerase (NEB) and the primers JOL13 and JOL14, which allowed for the addition of an N-terminal NotI restriction site (RS) followed by the linker GGTAGTGGAAGTGGTAGT, as well as a C-terminal KpnI RS after the stop codon. This amplicon was then ligated into the pUAST attB Drosophila transgenesis vector, thus forming the hereafter referred to as pUAST-mCherry-C plasmid. In parallel, we PCR amplified the sequences for GA36, GR36, PR36, GA100, GR100 and PR100 [10] using the TaKaRa LA Taq polymerase (Takara Bio Inc.) and the following primers: GA36fwd: JOL26; GA36rev: JOL33; GR36fwd: JOL26; GR36rev: JOL34; PR36fwd: JOL26; PR36rev: JOL35; GA100fwd: JOL26; GA100rev: JOL28; GR100fwd: JOL26; GR100rev: JOL30; PR100fwd: JOL26 and PR100rev: JOL30. This allowed for the addition of an N-terminal EcoRI RS followed by the ATG initiation site, as well as a C-terminal NotI RS. These amplicons were first ligated into the pBlueScript $\mathrm{SK}(+)$ plasmid for amplification and subsequently subcloned into the pUAST-mCherry-C plasmid. As a control, we also PCR amplified mCherry using the primers JOL9 and JOL14, which allowed for the addition of an N-terminal EcoRI RS followed by the ATG initiation site, as well as a C-terminal NotI RS after the stop codon. This amplicon was then directly ligated into the pUAST attB plasmid.

To clone the GA200 and GA200-mCherry constructs, we PCR amplified the GA100 sequence [10] in two independent reactions using the TaKaRa LA Taq polymerase and then ligated them together. First, we used primers JOL26 and JOL69 to add an N-terminal EcoRI RS followed by the ATG initiation site, as well as a SmaI RS and an $\mathrm{XbaI} \mathrm{RS}$ at the $\mathrm{C}$ terminus. This amplicon was ligated into the pBlueScript $\mathrm{SK}(+)$ plasmid to obtain an EcoRI-ATG-GA100-SmaI-XbaI pBlueScript SK(+) plasmid. Second, we used JOL43 and JOL44 to add an Nterminal XbaI RS and a C-terminal stop codon followed by a NotI RS to GA100. Alternatively, we used JOL43 and JOL28 to add an N-terminal XbaI RS and a C-terminal NotI RS without a stop codon to GA100. The former was ligated into the EcoRI-ATG-GA100-SmaI-XbaI pBlueScript SK(+) plasmid to generate an EcoRI-ATG-GA100SmaI-XbaI-GA100-Stop-NotI pBlueScript SK(+) plasmid, which was then subcloned into the pUAST attB plasmid (hereafter referred to as GA200). The latter was ligated into the EcoRI-ATG-GA100-SmaI-XbaI pBlueScript SK(+) plasmid to generate an EcoRI-ATG-GA100-SmaI- 
XbaI-GA100-NotI pBlueScript SK(+) plasmid, which was subcloned into the pUAST-mCherry-C plasmid, thus forming the hereafter referred to GA200-mCherry plasmid. To achieve high expression levels, all constructs contained the CACC Kozak sequence before their ATG initiation site. Finally, the sequence of all plasmids was verified by Sanger sequencing (Eurofins Genomics).

The sequences of all primers used for this study are included in Table 1.

Constructs were inserted into the fly genome using the phiC31 and attP/attB integration system [23]. For comparisons across the different DPRs, the landing site attP40 was used (i.e., Fig. 1 \& Additional file 1: Figure S1, Additional file 2: Figure S2 and Additional file 3: Figures S3), whereas for comparisons across the different repeat lengths of GA the landing site attP2 was used (i.e., Figs. 2, 3, 4).

For all experiments, female Gal4 driver flies were crossed with UAS or wild-type (WT) male flies. To generate the final genotypes of the driver flies used for the propagation experiments, the orco-Gal4 and R9D03-Gal4 genes were recombined with UAS-syt.eGFP and UASeGFP.NLS, respectively. These flies were then crossed with tub-Gal80 ${ }^{\text {ts }}$ flies and stable stocks were generated carrying the following genotypes: $\mathrm{w}^{-} ; \mathrm{w}$, tub-Gal80 $0^{\text {ts }} ; \mathrm{w}$, orco-Gal4, w, UAS-syt.eGFP and $\mathrm{w}^{-}$; w, tub-Gal80 ${ }^{\text {ts }}$; w, R9D03-Gal4, w, UAS-eGFP.NLS.

\section{Staining and imaging of adult Drosophila brains}

Brains of adult female flies were dissected in PBS and immediately fixed in $4 \%$ paraformaldehyde at $4{ }^{\circ} \mathrm{C}$ for 2 h. Tissues were then washed $4-6 \times 30 \mathrm{~min}$ in PBT (PBS with $0.5 \%$ Triton $\mathrm{X}-100$ ) at room temperature (RT). For experiments where the mCherry and eGFP signals were imaged, brains were subsequently incubated in 50\% glycerol in PBS for $1 \mathrm{~h}$ at RT after washing and mounted in VectaShield Antifade Mounting Medium with DAPI (Vectorlabs). For experiments where GA or GR were immunostained, brains were blocked in PBT with $5 \%$ fetal bovine serum and $0.01 \%$ sodium azide for $1 \mathrm{~h}$ at $\mathrm{RT}$ after initial washing and incubated with a mouse monoclonal anti-GA antibody (1:3000, Merck Millipore) or the $5 \mathrm{H} 9$ antibody against polyGR $(1: 50,[24])$ overnight at $4{ }^{\circ} \mathrm{C}$. Following 4-6 $30 \mathrm{~min}$ washes in PBT at RT, brains were incubated with a suitable Alexa Fluor Secondary Antibody (Molecular Probes) overnight at $4{ }^{\circ} \mathrm{C}$. Finally, brains were washed $4-6 \times 30 \mathrm{~min}$ in PBT, incubated in glycerol-PBS and mounted.

To label cell membranes, brains were incubated in a rhodamine-conjugated phalloidin solution (Life Technologies) diluted in PBT at $0.2 \mathrm{U} / \mathrm{ml}$ for $15 \mathrm{~min}$ at RT. Brains were subsequently washed $3 \times 30 \mathrm{~min}$ in PBT, incubated in glycerol-PBS and mounted.

Series of $2-\mu \mathrm{m}$ z-stacks across the whole fly brain were taken for each image using a Leica SP8-DLS confocal microscope and the same settings were used across genotypes and ages, unless otherwise stated. In experiments where DPR propagation was investigated, brains were imaged with settings where propagated puncta were overexposed, both in the case of the GA100 and the GA200 constructs, and where the signal in the negative control, devoid of any DPR construct, was minimal. This was done in an attempt to maximize the detectability of signal. To further maximize the detectability of specific signal, HyD detectors, gating and the excitation wavelength that

Table 1 List of primers

\begin{tabular}{|c|c|c|}
\hline Primer name & Primer sequence & Purpose \\
\hline $\mathrm{JOL} 13$ & $\begin{array}{l}\text { ATATGCGGCCGCCGGTAGTGGAAGTGGTAG } \\
\text { TGTGAGCAAGGGCGAGGAG }\end{array}$ & Generation of pUAS T-mCherry-C \\
\hline $\mathrm{JOL} 14$ & CCCCGGTACCTCACTTGTACAGCTCGTCCATG & Generation of pUAS T-mCherry-C and mCherry-only pUAST plasmids \\
\hline JOL26 & ATATGAATTCGGATCCCACCATG & $\begin{array}{l}\text { Generation of GA36-mCherry, GR36-mCherry, PR36-mCherry, GA100-mCherry, } \\
\text { GR100-mCherry and PR100-mCherry, GA200 and GA200-mCherry plasmids }\end{array}$ \\
\hline $\mathrm{JOL} 33$ & AAGCGGCCGCTGAAGCG & Generation of GA36-mCherry plasmid \\
\hline $\mathrm{JOL} 34$ & AAGCGGCCGCTGATCTGC & Generation of GR36-mCherry plasmid \\
\hline $\mathrm{JOL} 35$ & AAGCGGCCGCTGATCTGG & Generation of PR36-mCherry plasmid \\
\hline JOL28 & AAAAGCGGCCGCTGATGCTC & Generation of GA100-mCherry plasmid \\
\hline $\mathrm{JOL} 30$ & AAAAGCGGCCGCTGAACGTC & Generation of GR100-mCherry plasmid \\
\hline $\mathrm{JOL} 34$ & AAAAGCGGCCGCTGATCGAG & Generation of PR100-mCherry plasmid \\
\hline JOL9 & AAAAGAATTCCAACATGGTGAGCAAGGGCGAG & Generation of the mCherry-only pUAST plasmids \\
\hline JOL69 & $\begin{array}{l}\text { CCGCGGCCGCTCTAGACCCGGGTGATGCTC } \\
\text { CTGCTCC }\end{array}$ & Generation of the GA200 and GA200-mCherry plasmids \\
\hline $\mathrm{JOL} 43$ & GAATTCGGATCCCACCATGTCTAGAGGAGCT & Generation of the GA200 and GA200-mCherry plasmids \\
\hline $\mathrm{JOL} 44$ & CTTGCGGCCGCTTATGCTCC & Generation of the GA200 and GA200-mCherry plasmids \\
\hline JOL28 & AAAAGCGGCCGCTGATGCTC & Generation of the GA200 and GA200-mCherry plasmids \\
\hline
\end{tabular}


maximized the fluorescence emission of all fluorophores were used in all cases during imaging.

\section{Quantification of confocal images and statistics}

All confocal images acquired for experiments where DPR spread was tested were first processed using ImageJ before subjecting them to quantification analysis. First, maximum z-stack projections were obtained to identify the lamina surrounding the optic lobes, as well as distinct artifacts, which were cropped from the stacks. In addition, areas of initial expression induction were also removed. For the latter, brain regions positive for eGFP were identified and cropped in experiments where eGFP was co-expressed along with the relevant DPR (i.e., Figs. 1, 3 \& Additional file 3: Figure S3). This included the ORN axons and synaptic terminals for Fig. 1 and Additional file 3: Figure S3, or the medulla of the optic lobes, as well as a distinct region in the antennal lobes, when the OL driver was used. Alternatively, a rectangle spanning the visually detectable antennal lobes and the rest of the lower part of the central brain was drawn in experiments where eGFP was not co-expressed (i.e., Figs. 2 \& 4), and its content was also cropped to ensure that no puncta within the axons or the terminals of ORNs were included in the quantification of propagated puncta. Puncta in the remaining brain areas were quantified from the cropped z-stacks in 3D using the image analysis software Imaris 9.2.0 (Oxford Instruments). After background correction, the built-in spot detection algorithm was used to identify spots with a minimum size of $500 \mathrm{~nm}$. Detection settings were adjusted based on the maximum intensity of the spots, which proved the most accurate filter to distinguish between strongly labelled spots (considered as real GA puncta) and weak/ low quality spots from trachea or background. The same parameters were used for all of the conditions compared in the same experiment.

For the quantification of eGFP or GA levels in ORNS, we used their fluorescent signal in the ORN terminals in the antennal lobes as a proxy for their overall levels. Briefly, whole-brain stacks were taken with nonsaturating settings for the ORN eGFP or GA signals, maximum intensity projections were generated from each z-stack, and the mean intensity of eGFP or GA in the synaptic terminals of ORNs was measured using ImageJ. The same settings were used for all of the conditions compared in the same experiment.

Statistical analysis was performed using GraphPad Prism. Individual statistical tests are indicated in the figure legends. Both One-way and Two-way ANOVA were always followed by Bonferroni post hoc test. $P$ values < 0.05 were considered significant: ${ }^{*} P<0.05$, ${ }^{* *} P<0.01$, ***:P $P<0.001$ and ${ }^{* * * * *} P<0.0001$.

\section{Results}

GA DPRs, but not GR or PR DPRs, spread rapidly in the fly brain

To address whether toxicity-associated DPRs can spread in vivo, we generated novel fly lines that expressed mCherry-tagged GA, GR or PR with 36 or 100 repeats (hereafter GA36, GR36, PR36, GA100, GR100 and PR100) in a UAS-transgene. All transgenes were integrated into the same genomic locus, the attP40 landing site, which we previously confirmed to produce equal transcript levels of untagged DPRs [10]. mCherry-tagged DPRs were used in an effort to avoid differences in sensitivity of the different DPR-specific antibodies. To confirm expression of the DPR constructs, we generated flies with pan-neuronal induction of each of the mCherry-tagged DPRs, using the inducible elav-GS system, and imaged the mCherry signal in adult fly brains after induction for 3 days. Expression of all the DPR36-mCherry fusion proteins could be detected by imaging their mCherry signal (Additional file 1: Figure S1). The signal from the PR36-mCherry flies was stronger than that of GA36-mCherry and GR36-mCherry, probably due to the previously reported nuclear location of PR [25, 26]. However, while we detected the mCherry signal from mCherry-tagged GA100 and PR100 pan-neuronally (Additional file 2: Figure S2A-C), the presence of GR100mCherry could only be verified when a GR-specific antibody was used (Additional file 2: Figure S2D-E). Interestingly, the expression of GR100-mCherry was almost exclusively detected in the median neurosecretory cells (MNCs) in the pars intercerebralis, where the expression levels of the majority of the DPRs tested, but not mCherry only, was also particularly high (Additional file 1: Figure S1 and Additional file 2: Figure S2). This suggests that MNCs may be particularly vulnerable to the accumulation of the C9 DPRs.

We next addressed whether the toxic DPRs have the ability to spread in vivo. Given that a previous study reported propagation of mutant huntingtin from Olfactory Receptor Neurons (ORNs) to other brain regions in $D$. melanogaster [27], we also initiated expression in this brain area. We imaged the brains of flies where ORNspecific expression of GA36-mCherry, GR36-mCherry or PR36-mCherry had been induced for 3 days in the adult fly using a temperature-inducible Gal80 and the ORNspecific orco-Gal4 driver [21,28]. Since the cell bodies of ORNs are outside the central brain, and therefore only the axonal projections and synaptic terminals of ORNs can be detected in the adult central brain of Drosophila after dissection, we co-expressed eGFP-tagged synaptotagmin to label ORNs and control for driver specificity [29]. No specific mCherry signal was found outside of ORNs (Additional file 3: Figure S3), suggesting that the short isoforms of the toxic DPRs cannot spread, at least after short-term expression from this location. Interestingly, when flies 

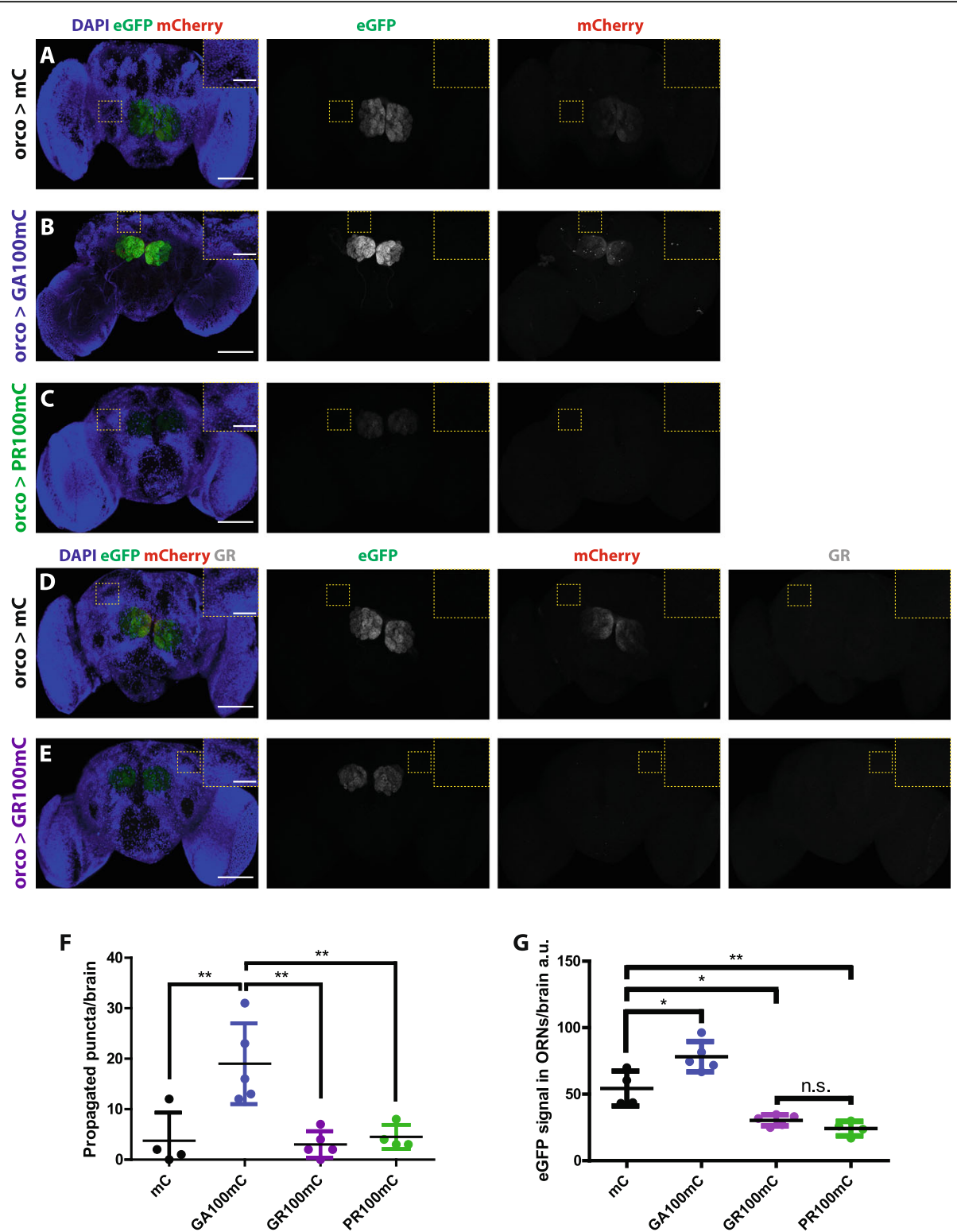

Fig. 1 GA100-mCherry, but not GR100-mCherry or PR100-mCherry, can spread outside of ORNs. a-e Representative images of 5-days-old fly brains expressing mCherry (a \& d), GA100-mCherry (b), PR100-mCherry (c) or GR100-mCherry (e) in Olfactory Receptor Neurons (ORNs) for 3 days. The same settings were applied to all genotypes while imaging their eGFP and mCherry signals. Spreading was only observed in flies expressing GA100-mCherry. EGFP and mCherry were detected using fluorescence as read-out. A GR-specific antibody was used to detect GR100-mCherry (e) and $m$ Cherry $(\mathbf{d})$. Fly brains expressing only mCherry ( $\mathbf{a} \& \mathbf{d}$ ) were used as control to show that mCherry cannot spread by itself and to verify antibody specificity (d). Insets of the highlighted brain regions are shown. $\mathbf{f}$ Quantification of the number of mCherry puncta detected outside of ORNs across genotypes per brain after induction for 3 days. $\mathbf{g}$ Quantification of the eGFP signal detected within ORNs per brain ${ }^{* *} P<0.01$ and ${ }^{*} P<0.05$; One-way ANOVA, $n=4-6$ ). Scale bars in images and insets are 100 um and 10 um, respectively

were induced to express GA100-mCherry, GR100mCherry or PR100-mCherry in ORNs for 3 days, mCherry-positive puncta were exclusively detected outside of the ORNs of GA100-mCherry-expressing flies (Fig. 1a-f), suggesting that longer GA DPRs are particularly prone to spread. Moreover, we detected a strong reduction in the eGFP fluorescence within the ORNs of flies expressing GR100-mCherry and PR100-mCherry (Fig. 1ae, g), which may result from the well-known inhibitory effect of the arginine-rich DPRs on translation [30]. Also of note, unlike for GA100-mCherry, no specific mCherry signal was detected in the axons or synaptic terminals of ORNs in GR36-mCherry-, PR36-mCherry-, GR100mCherry- or PR100-mCherry-expressing flies 


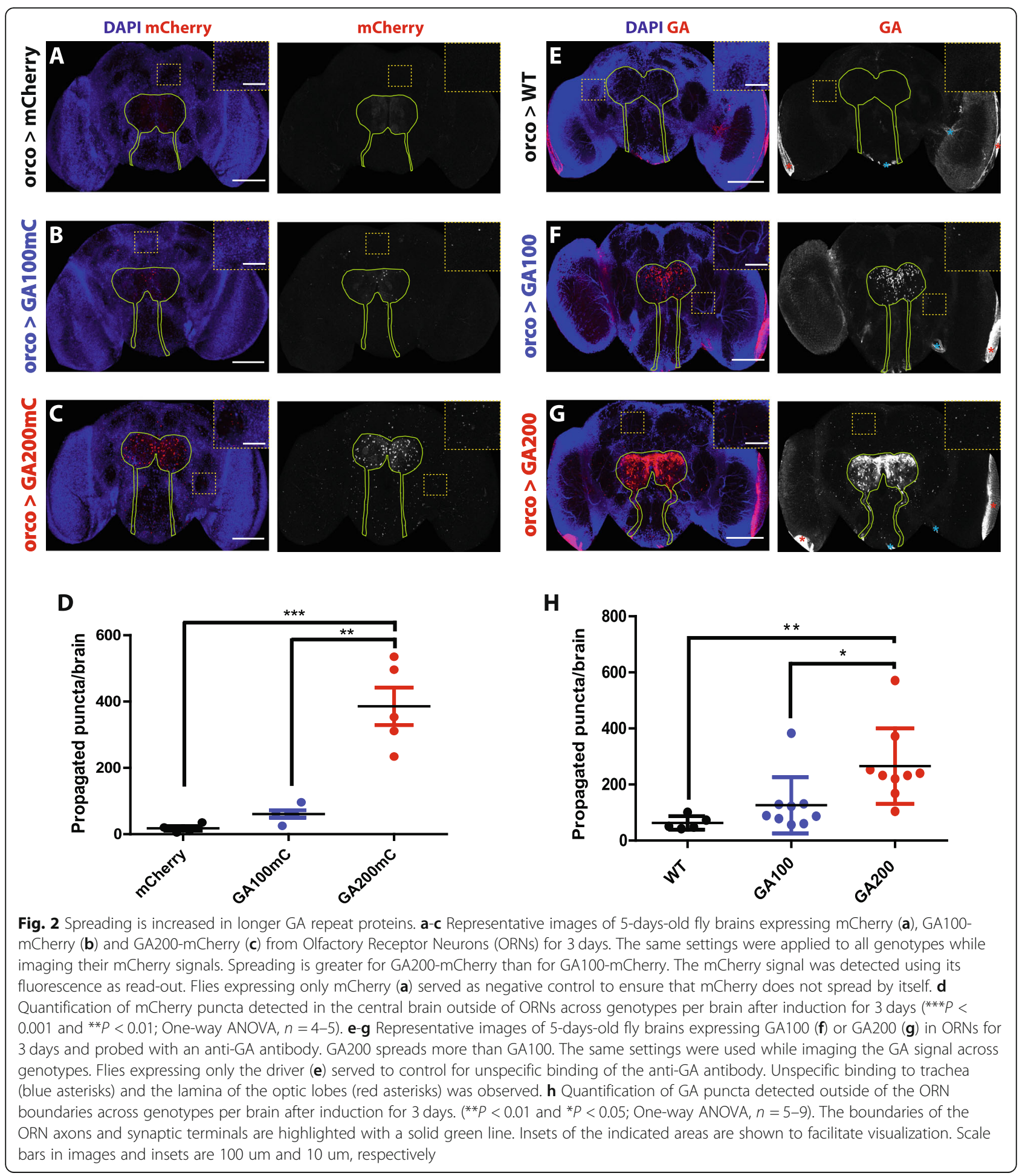

(Additional file 3: Figure S3C, D), indicating that these DPRs are not transported along axons, a potential requirement for DPR spread. Altogether, our data indicate that, out of the three toxic DPRs, at least for DPRs up to 100 repeats in length, only GA can spread from ORNs to the rest of the central brain.
GA repeat length modulates the spread of GA DPRs Unlike GA100-mCherry, GA36-mCherry did not spread, suggesting that spread is repeat length-dependent. To test this hypothesis further, we generated novel fly lines expressing mCherry-tagged GA100 and GA200 from the same genomic locus (attP2 landing site) to ensure equal 

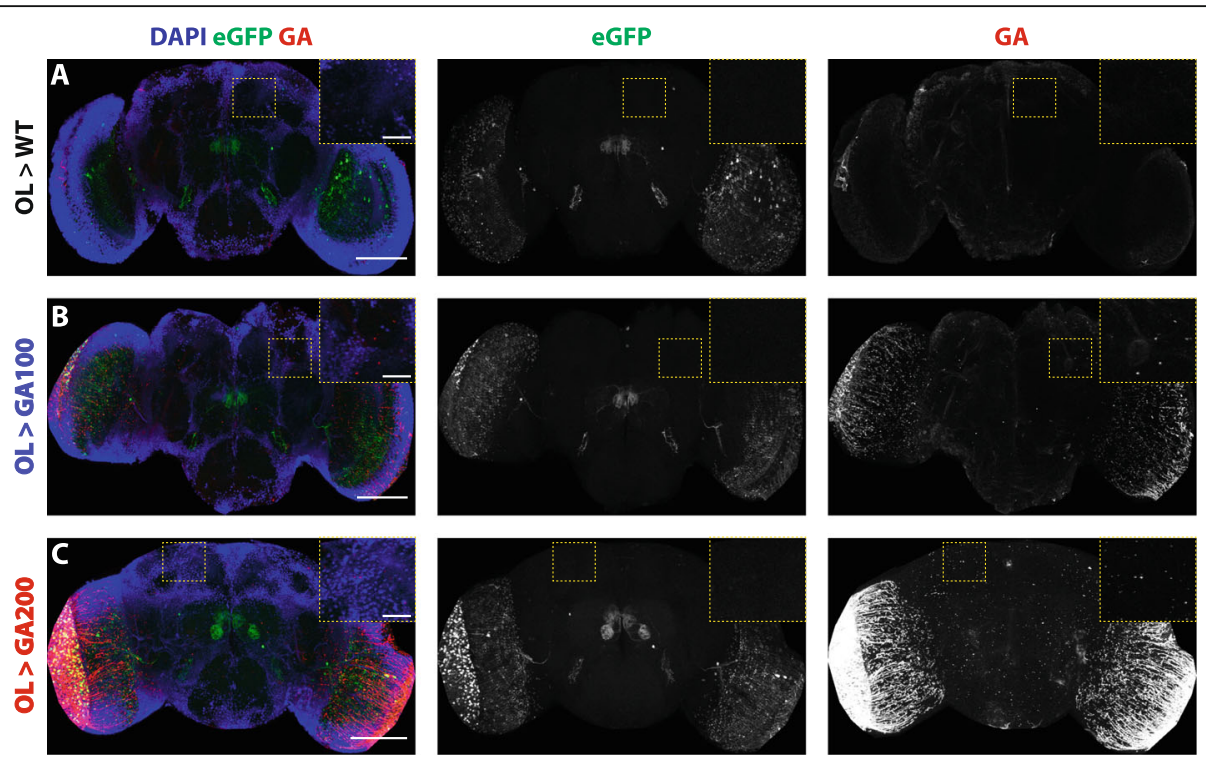

D

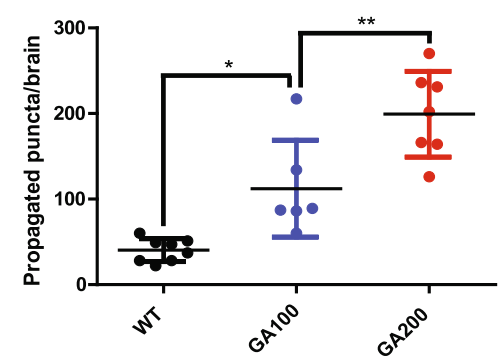

Fig. 3 GA spreads in a repeat length-dependent manner from an independent neuronal population. a-c Representative images of 5-days-old fly brains from (a) control flies, expressing only the Optic Lobe (OL)-Gal4 driver, (b) flies expressing GA100 or (c) GA200 in the OLs for 3 days and probed with an anti-GA antibody. GA200 also spreads more than GA100 from this brain region. The same settings were used while imaging the GA signal across genotypes. EGFP with a nuclear localization signal was co-expressed to identify the cells targeted by the OL-Gal4 driver. $\mathbf{d}$ Quantification of GA puncta detected in the central brain outside of the targeted cells after expression of the indicated constructs for 3 days. Flies expressing only the driver (a) were used to control for unspecific binding of the anti-GA antibody ${ }^{* *} P<0.001$ and ${ }^{*} P<0.05$; One-way ANOVA, $n=6-8$ ). Insets of the indicated areas are shown to facilitate visualization. Scale bars in images and insets are 100 um and 10 um, respectively

transcript levels. In addition, to exclude the possibility that co-expression of eGFP-tagged synaptotagmin could influence transmission, we only expressed polyGAmCherry. We measured the spread of the two mCherrytagged constructs from ORNs, and found accumulation of mCherry puncta of both DPRs outside of this neuronal population after 3 days of expression induction, with substantially greater spread of the 200 than the 100 GA DPR (Fig. 2a-d). Spreading of GA was therefore more pronounced with longer repeats and was independent of eGFP-tagged synaptotagmin co-expression.

Since tags can interfere with protein function [31], we next tested the spread of untagged GA DPRs using GA100 and GA200 expressed in ORNs and a GAspecific antibody [32]. In agreement with our results using mCherry-tagged GA constructs, we found that the number of GA puncta detected outside of ORNs greatly increased with repeat length (Fig. 2e-h), further supporting the notion that the propensity of GA to spread is greater with longer GA repeats. To determine if GA could spread from different types of neurons, we tested whether untagged GA was transmitted from the optic lobes (OL). We expressed the GA constructs along with nuclear eGFP for 3 days in the OLs using the R9D03-Gal4 driver [33] and, consistent with our finding in ORNs, GA also spread in a repeat-length dependent manner from the OLs (Fig. 3a-d).

To determine if the propagated GA enters recipient cells, we co-stained brains from flies expressing GA200 in ORNs with fluorescently labelled phalloidin, a dye that strongly binds to actin $\mathrm{F}$ and can therefore be used to identify the boundaries of single cells in tissue [34]. Using this approach, we detected GA positive puncta in the cytoplasm of recipient cells, thus indicating that propagated GA puncta are intracellular (Additional file 4: Figure S4). 

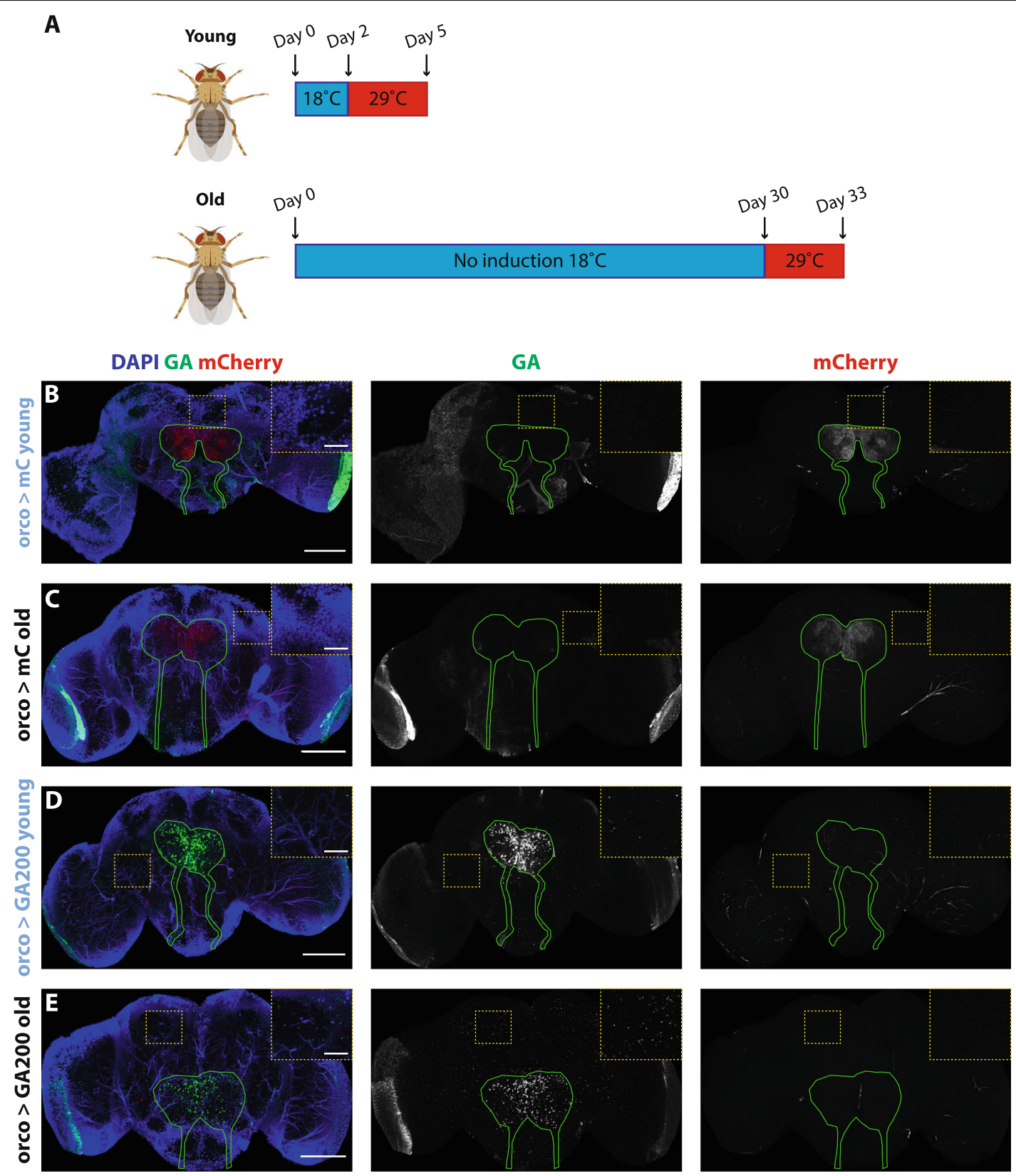

$\mathbf{F}$

G
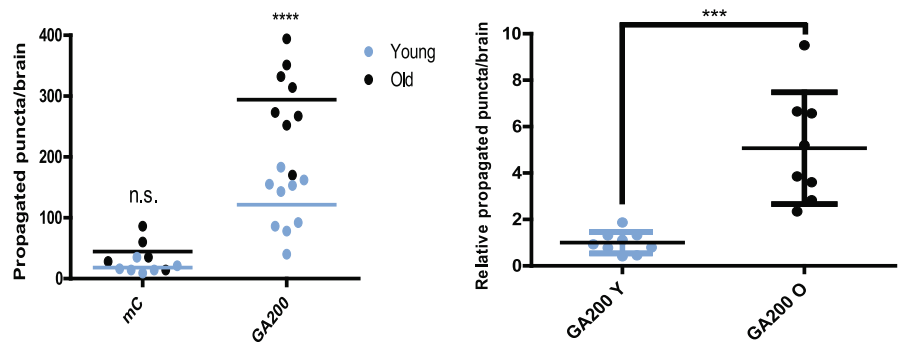

Fig. 4 (See legend on next page.) 


\section{(See figure on previous page.)}

Fig. 4 Age-associated factors exacerbate GA spread. aThe expression of GA200 was induced for 3 days in Olfactory Receptor Neurons (ORNs) in young ( 2 days old) and old flies (30 days old), after which GA spread was measured. Fly cartoons were created with BioRender. b \& $\mathbf{c}$ Representative images of control fly brains expressing mCherry in ORNs for 3 days in young (a) or old (b) flies. d \& e Representative images of fly brains expressing GA200 in ORNs for 3 days in young (d) and old (e) animals. Brains were probed with an anti-GA antibody. The outline of ORN axons and synaptic terminals is shown in green. Insets of indicated areas highlight differences in the number of propagated dots across conditions. $\mathbf{f}$ Quantification of the total number of GA-positive dots detected outside of ORNs after 3 days of expression in young and old flies (age: ${ }^{* * *} P<0.0001$; genotype: ${ }^{* * *} P<0.0001$; interaction: ${ }^{* * *} P<0.001$; Two-way ANOVA, $n=5-9$ ). g Quantification of the number of propagated GA-positive dots relative to the GA signal in ORNs after 3 days of expression in young and old flies ( ${ }^{* * *} P<0.001$, t-test). Scale bars in images and insets are 100 um and 10 um, respectively

Altogether, our results show that, in two independent neuronal subsets, longer GA repeats spread in a lengthdependent manner.

\section{GA DPRs exhibit an age-related increase in spreading} Given that ageing is a major risk factor for ALS and FTD [35], we investigated whether GA spread was affected by the age at which we induced GA expression. We induced ORN-specific expression of untagged GA200 starting in 2-day-old or 30-day-old adult flies for 3 days, and measured the spread outside of ORNs (Fig. 4a). There was a 3-fold increase in the total number of propagated GA puncta when GA expression was induced at the older age (Fig. 4b-f). Given that the accumulation of the peptides could change after expression induction at different ages, we also quantified the cumulative number of propagated GA puncta relative to GA expression in ORNs, as an indicator of whether the proportion of propagated GA compared to the total amount of GA in ORNs would change at different ages. Indeed, we found a larger proportion of propagated GA compared to ORN GA after expression induction in older brains (Fig. 4g), thus showing that the increased spread in older brains is not simply due to changes in the accumulation of GA in ORNs upon expression in older brains. Collectively, these results suggest that ageassociated factors strongly affect the propagation propensity of GA DPRs.

\section{Discussion}

In this study, we have explored whether the toxic C9 DPRs, namely GA, GR and PR, can spread, and the contributions of DPR repeat length and age to propensity to spread in vivo. Using the brain of adult Drosophila as a model, we show that GA, but not GR and PR, DPRs spread out of ORNs, at least as soon as 3 days after expression induction, and could therefore be a relevant early event in the pathogenesis initiation of C9 ALS and C9 FTD. In addition, while 36-repeat GA did not show evidence of spread, transmission occurred with expression of 100 and, to a greater extent, with $200 \mathrm{GA}$ repeats. Finally, GA spread was more marked when its expression was induced at an older age.
Recent studies have shown that some proteins that typically aggregate in the brains of patients with various neurodegenerative diseases can be transmitted in model organisms. These findings have led to the hypothesis that protein transmission could underpin the clinical progression of such patients [14]. For instance, the clinical progression of ALS and FTD may be explained by the progressive spreading of TDP-43 pathology across conserved neuronal circuits relevant to these diseases $[14,16,36,37]$. To investigate whether the toxicityassociated DPRs derived from a mutation in the C9orf72 gene could also spread under in vivo conditions, we first used flies expressing, exclusively in ORNs, mCherry-tagged constructs of GA, GR and PR, to avoid an antibody bias, as antibodies specific for different DPRs could have different sensitivities. Interestingly, unlike mutant huntingtin, which strongly spread to a pair of large posterior neurons in the posterior protocerebrum upon expression in ORNs [27], the spreading pattern of GA DPRs was not specific to a single neuronal subset, either upon expression from ORNs or OLs, which might indicate that GA transmission does not only occur through synapses in vivo. By performing co-stainings with the cell membrane dye phalloidin, we found that the propagated GA signal accumulates in the shape of aggregate-like puncta inside recipient cells, which adds GA onto the growing list of proteins shown to spread from cell to cell in in vivo models of neurodegenerative diseases. In fact, GA accumulates in intracellular aggregates and is the most widely detected DPR in patient tissue $[8,13]$, which may be at least partially attributable to this ability to spread. Our result is also in line with a previous cell culture study, where GA, but not GR or PR, was found to spread from cell to cell [19]. Future studies should address what mechanisms are activated by GA, and not by GR or PR, that could be associated with its release from DPR-expressing neurons and/or its uptake by recipient neurons. While expression of the argininerich DPRs has been mostly associated with translation inhibition [38, 39], impairment of nucleocytoplasmatic transport [40-42], RNA processing [25, 43-45] and dysfunction of stress granule dynamics [39, 46], GA expression has been strongly correlated with impairment 
of proteostasis $[47,48]$. Indeed, we observed that the co-expression of eGFP-tagged synaptotagmin with mCherry-tagged GR and PR led to decreased eGFP signal, which is likely due to their well-known inhibitory effect on translation [30]. In contrast, when we coexpressed mCherry-tagged GA, we found increased eGFP signal, suggesting that GA may be impairing eGFP degradation by damaging the proteostasis machinery. Therefore, we hypothesize that the preferential spread of GA could be associated with GA-induced proteostasis impairment, which has been shown to exacerbate the release of toxic proteins [49]. Another non-exclusive reason why GA, but not GR or PR, may spread could be related to the differential ability of neurons to transport each DPR along axons. In fact, unlike GA, we did not detect GR or PR in the axons or synaptic terminals of ORNs. Furthermore, GA, unlike GR and PR, has been shown to form oligomeric amyloids [17], which have been associated with greater propensity to spread [50]. This feature could also account for the greater propensity of GA to spread compared to GR and PR.

Unlike the distribution of phosphorylated TDP-43, which has been proposed to occur in patients in a progressive pattern indicative of pathology spread [36, 37], DPR aggregates have not yet been shown to occur in a staged manner. Thus, an argument against the relevance of DPR spreading is that they are produced by all cells expressing C9orf72, so do not necessarily need to receive an aggregate from a neighboring/connected cell to allow aggregate formation. However, it is possible that the addition of exogenous GA seeds could initiate aggregation of non-aggregated GA molecules, thus speeding up the process in receiver cells. How this might lead to TDP-43 changes is an open question but several possibilities exist. First, several studies have shown that GA itself can trigger cytoplasmic accumulation and hyperphoshorylation of TDP-43 [32, 51, 52]. Therefore, given that GA transmission would exacerbate the accumulation of GA, it could play a relevant role in eliciting the cytoplasmic accumulation and aggregation of TDP-43, which would then spread across the neuronal circuits relevant to ALS/FTD symptoms. This idea is supported by reports that the accumulation of GA aggregates precedes TDP-43 pathology [8,53-55]. Second, one in vitro study showed that GA can spread within exosomes [18], which are known to comprise different kinds of biological material, including TDP-43 [56]. Therefore, GA accumulation could favour the formation of secretory vesicles, like exosomes, which would comprise, apart from GA aggregates, TDP-43 seeds or other material that would contribute to the degeneration of the ALS/ FTD-relevant neuronal circuits. Indeed, the relevance of exosomes in the transmission of aggregation-prone proteins has already been shown in vivo [57]. Finally, while GA aggregates do not strongly correlate with neurodegeneration, or TDP-43 pathology [58], it cannot be excluded that specific forms of GA, e.g., oligomers or aggregates of a specific size, potentially not detected by inclusion staining, may correlate better with ALS/FTD neurodegeneration and TDP-43 pathology than the overall burden of GA aggregates. However, this point remains completely unexplored.

Both the morphology and spreading propensity of GA DPRs is dependent on repeat lengths. In the adult fly brain, GA36-mCherry shows a diffuse staining and does not spread. In contrast, GA100-mCherry and GA200mCherry look aggregated and spread in a repeat lengthdependent manner. These differences highlight the relevance of testing DPRs of different lengths to fully understand the behaviour of these peptides, and support future in-depth studies to understand the effect that repeat size has in the C9orf 72 mutation context in humans, which remains controversial [59-61] . In the case of the untagged GA DPRs, differences in GA transmission could be confounded by the GA antibody having more epitopes to bind to in the longer constructs, which would lead to stronger propagation signal being detected for GA200 than for GA100. However, this is unlikely because we also see greater spread for mCherry-tagged GA200 compared to mCherry-tagged GA100 when directly recording the mCherry fluorescence signal, which is only influenced by the overall abundance of each DPR as both GA100mCherry and GA200-mCherry carry one mCherry tag per polyGA molecule. Given that the amino acid composition of GA100 and GA200 DPRs is the same, we hypothesize that the longer GA DPRs spread more either because they are more difficult to degrade, presumably due to their greater propensity to aggregate or their stronger effect on proteostasis, or because they earlier acquire a conformation that triggers their transmission. For instance, tau and $\alpha$-synuclein, which typically aggregate and spread in Alzheimer's disease and Parkinson's disease models respectively, need to be at least partially aggregated to be able to propagate [14].

Ageing is a major risk factor for ALS and FTD [35]. We found that GA spread is greater when its expression is induced at a later age, suggesting that ageingassociated factors, such as impaired proteostasis, promote DPR spread, and therefore that GA transmission is likely to occur at a greater rate at old ages. These findings are in agreement with a recent study that reported a 2-fold increase in the spreading rate of tau upon injection of human tau-expressing viruses in aged murine brains compared to young ones [62]. For instance, GA aggregates may be degraded when they are formed at a young age, when the proteostasis machinery works efficiently, but accumulate during the progressive decline of 
proteostasis activity during ageing. The excessive accumulation of GA aggregates could trigger their mislocalization to exocytotic vesicles, thus mediating their extracellular release.

Taken together, we show that GA DPRs can rapidly spread in vivo, which is strongly influenced by their repeat length and the age of the GA-expressing neurons. The wide range of available tools to genetically manipulate flies makes this Drosophila model of early in vivo GA spread an attractive system that could be used in genetic or pharmacological screens to gain further insights into the mechanism(s) underlying GA transmission, its consequences for the recipient tissue and the search for interventions that can abolish this event.

\section{Conclusions}

In conclusion, we have provided the first evidence for transmission of GA DPRs in an in vivo setting using the adult fly brain as a complex model. The extent of spread was magnified for longer GA DPRs and upon expression in old flies, suggesting that this mechanism could be of relevance for both the initiation and the progression of C9 ALS and C9 FTD.

\section{Supplementary information}

Supplementary information accompanies this paper at https://doi.org/10. 1186/s40478-019-0860-x.

Additional file 1: Figure S1. mCherry-tagged DPR36 constructs can be detected by imaging their endogenous mCherry signal. A-E show representative images of 5-days-old adult fly brains from flies induced to panneuronally express each of the indicated mCherry-tagged DPR36 construct for 3 days. 10 times lower settings were used to image mCherry (B) and PR36mCherry (E), as the signal was much stronger in those genotypes. For the rest of the genotypes, the settings were the same. No antibodies were used. Insets highlight the brain area where Median Neurosecretory Cells (MNCs) are located. Scale bars in images and insets are $100 \mathrm{um}$ and $10 \mathrm{um}$, respectively.

Additional file 2: Figure S2. Detection of mCherry-tagged DPR100 proteins upon pan-neuronal expression. A-E Representative images of 5days-old adult fly brains that pan-neuronally express the indicated mCherry-tagged DPR100 constructs for 3 days. 10 times lower settings were used to image GA100mCherry (B) and mCherry (D) as the signal was much stronger in those genotypes. No antibodies were used for A-C. D-E Fly brains were stained with an anti-GR antibody. GR100mC can be most clearly detected in the brain area where Median Neurosecretory Cells (MNCs) are located. Insets of the indicated areas are shown to facilitate visualization. Scale bars in images and insets are $100 \mathrm{um}$ and $10 \mathrm{um}$, respectively.

Additional file 3: Figure S3. GA36-mCherry, GR36-mCherry and PR36mCherry cannot spread from ORNs. A-D Representative images of 5-daysold fly brains expressing GA36-mCherry (B), GR36-mCherry (C) or PR36mCherry (D) in Olfactory Receptor Neurons (ORNs) for 3 days.

Synaptotagmin-eGFP was co-expressed in all genotypes to identify ORNs. Flies expressing mCherry (A) were used as a negative control to ensure that mCherry cannot spread by itself. No antibodies were used. Insets of the indicated areas are also shown to facilitate visualization. Scale bars in images and insets are $100 \mathrm{um}$ and $10 \mathrm{um}$, respectively.

Additional file 4: Figure S4. GA propagated puncta are intracellular. A Representative image of a 5-days-old fly brain expressing GA200 in
Olfactory Receptor Neurons (ORNs) for 3 days, and stained with an antiGA antibody (green) and the rhodamine-conjugated fluorophore phalloidin (red). Scale bar $=25 \mathrm{um}$. B Inset of the area highlighted in a yellow dotted square in A outside of the ORN synaptic terminals where GA has propagated. Five cells positive for GA intracellular puncta can be observed. Scale bar $=3$ um.

\section{Abbreviations}

ALS: Amyotrophic lateral sclerosis; C9orf72: Chromosome 9 open reading frame 72; DPR: Dipeptide repeat; eGFP: Enhanced green fluorescent protein; FTD: Frontotemporal dementia; GA: Glycine-alanine; GP: Glycine-proline; GR: Glycine-arginine; MNCs: Median neurosecretory cells; OL: Optic lobe; ORN: Olfactory receptor neurons; PA: Proline-alanine; PR: Proline-arginine; RAN: Repeat-associated non-AUG; RS: Restriction site; TDP-43: TAR DNAbinding protein of $43 \mathrm{kDa}$; WT: Wild-type

\section{Acknowledgements}

The $5 \mathrm{H} 9$ anti GR antibody was a generous gift from Friederich A. Grässer [24]. Imaging analyses were performed in the FACS \& Imaging Core Facility at the Max Planck Institute for Biology of Ageing. Stocks obtained from the Bloomington Drosophila Stock Center (NIH P40OD018537) were used in this study. We are also grateful to Natalia Kononenko (CECAD), David Vilchez (CECAD) and Teresa Niccoli (UCL) for helpful comments on the manuscript. Javier Morón-Oset received support by the Cologne Graduate School of Ageing Research, which is funded by the Deutsche Forschungsgemeinschaft (DFG), German Research Foundation under Germany's Excellence Strategy EXC 2030/1, Project-ID 390661388.

\section{Authors' contributions}

JMO, SG and LP designed the study; JMO performed cloning; JE injected plasmids for the generation of transgenic flies; JMO performed fly crossings; JMO and TS performed immunostainings, imaging and analysis; JMO, AMI, SG and LP wrote the manuscript. All authors read and approved the final manuscript.

\section{Funding}

This work was funded by the Max Planck Society and the Wellcome Trust (WT098565/Z/12/Z).

\section{Availability of data and materials}

All data generated or analysed during this study are included in this published article (and its supplementary information files).

Ethics approval and consent to participate

Not applicable.

\section{Consent for publication}

Not applicable.

\section{Competing interests}

The authors declare that they have no competing interests.

\section{Author details}

${ }^{1}$ Max Planck Institute for Biology of Ageing, Joseph-Stelzmann-Strasse 9b, 50931 Cologne, Germany. ${ }^{2}$ Department of Neurodegenerative Disease, UCL Institute of Neurology, Queen Square, London WC1N 3BG, UK. ${ }^{3}$ Department of Genetics, Evolution and Environment, Institute of Healthy Ageing, University College London, Darwin Building, Gower Street, London WC1E 6BT, UK.

Received: 18 October 2019 Accepted: 2 December 2019

Published online: 16 December 2019

\section{References}

1. Ling SC, Polymenidou M, Cleveland DW (2013) Converging mechanisms in als and FTD: disrupted RNA and protein homeostasis. Neuron 79:416-438. https://doi.org/10.1016/j.neuron.2013.07.033

2. DeJesus-Hernandez M, Mackenzie IR, Boeve BF, Boxer AL, Baker M, Rutherford NJ, Nicholson AM, Finch NA, Gilmer F, Adamson J, Kouri N, Wojtas A, Sengdy P, Hsiung G-YR, Karydas A, Seeley WW, Josephs KA, 
Geschwind DH, Wszolek ZK, Feldman H, Petersen R, Miller BL, Dickson D, Boylan K (2011) Expanded GGGGCC hexanucleotide repeat in non-coding region of C9ORF72 causes chromosome 9p-linked frontotemporal dementia and amyotrophic lateral sclerosis. Neuron 72:245-256. https://doi.org/10. 1016/j.neuron.2011.09.011.Expanded

3. Majounie E, Renton AE, Mok K, Dopper EGP, Waite A, Rollinson S, Chiò A Restagno G, Nicolaou N, Simon-Sanchez J, van Swieten JC, Abramzon Y, Johnson JO, Sendtner M, Pamphlett R, Orrell RW, Mead S, Sidle KC, Houlden H, Rohrer JD, Morrison KE, Pall H, Talbot K, Ansorge O, Hernandez DG, Arepalli S, Sabatelli M, Mora G, Corbo M, Giannini F, Calvo A, Englund E, Borghero G, Floris GL, Remes AM, Laaksovirta H, McCluskey L, Trojanowski JQ, Van Deerlin VM, Schellenberg GD, Nalls MA, Drory VE, Lu CS, Yeh TH, Ishiura H, Takahashi Y, Tsuji S, Le Ber I, Brice A, Drepper C, Williams N, Kirby J, Shaw P, Hardy J, Tienari PJ, Heutink P, Morris HR, Pickering-Brown S, Traynor BJ, Adamson G, Bayer AJ, Beck J, Callister JB, Blake DJ, Blumen SC, Collinge J, Dunckley T, Ealing J, East S, Elman L, Gerhard A, Guerreiro RJ, Gwinn K, Halliwell N, Hamdalla HH, Hewitt C, Ince P, Jablonka S, James C, Kent L, Knock JC, Lynch T, Mahoney C, Mann D, Neal J, Norris D, O'Dowd S, Richardson A, Rossor M, Rothstein J, Scholz SW, Snowden J, Stephan DA, Toulson G, Turner MR, Warren JD, Young K, Weng YH, Kuo HC, Lai SC, Huang CL, Camuzat A, Entraingues L, GuillotNoël VP, Clerget-Darpoux F, Corcia P, Couratier P, Didic M, Dubois B, Duyckaerts C, Guedj E, Golfier V, Habert MO, Hannequin D, Lacomblez L, Meininger V, Salachas F, Levy R, Michel BF, Pasquier F, Puel M, ThomasAnterion C, Sellal F, Vercelletto M, Moglia C, Cammarosano S, Canosa A, Gallo S, Brunetti M, Ossola I, Marinou K, Papetti L, Pisano F, Pinter GL, Conte A, Luigetti M, Zollino M, Lattante S, Marangi G, la Bella V, Spataro R, Colletti T, Battistini S, Ricci C, Caponnetto C, Mancardi G, Mandich P, Salvi F, Bartolomei I, Mandrioli J, Sola P, Lunetta C, Penco S, Monsurrò MR, Tedeschi G, Conforti FL, Gambardella A, Quattrone A, Volanti P, Floris G, Cannas A, Piras V, Marrosu F, Marrosu MG, Murru MR, Pugliatti M, Parish LD, Sotgiu A, Solinas G, Ulgheri L, Ticca A, Simone I, Logroscino G (2012) Frequency of the C9orf72 hexanucleotide repeat expansion in patients with amyotrophic lateral sclerosis and frontotemporal dementia: a crosssectional study. Lancet Neurol 11:323-330. https://doi.org/10.1016/S14744422(12)70043-1

4. Renton AE, Majounie E, Waite A, Simón-Sánchez J, Rollinson S, Gibbs JR, Schymick JC, Laaksovirta H, van Swieten JC, Myllykangas L, Kalimo H, Paetau A, Abramzon Y, Remes AM, Kaganovich A, Scholz SW, Duckworth J, Ding J, Harmer DW, Hernandez DG, Johnson JO, Mok K, Ryten M, Trabzuni D, Guerreiro RJ, Orrell RW, Neal J, Murray A, Pearson J, Jansen IE, Sondervan D, Seelaar H, Blake D, Young K, Halliwell N, Callister JB, Toulson G, Richardson A, Gerhard A, Snowden J, Mann D, Neary D, Nalls MA, Peuralinna T, Jansson L, Isoviita VM, Kaivorinne AL, Hölttä-Vuori M, Ikonen E, Sulkava R, Benatar M, Wuu J, Chiò A, Restagno G, Borghero G, Sabatelli M, Heckerman D, Rogaeva E, Zinman L, Rothstein JD, Sendtner M, Drepper C, Eichler EE, Alkan C, Abdullaev Z, Pack SD, Dutra A, Pak E, Hardy J, Singleton A, Williams NM, Heutink P, Pickering-Brown S, Morris HR, Tienari PJ, Traynor BJ (2011) A hexanucleotide repeat expansion in C9ORF72 is the cause of chromosome 9p21-linked ALS-FTD. Neuron 72:257-268. https://doi.org/10.1016/j.neuron. 2011.09.010

5. Gendron TF, Bieniek KF, Zhang YJ, Jansen-West K, Ash PEA, Caulfield T, Daughrity L, Dunmore JH, Castanedes-Casey M, Chew J, Cosio DM, Van Blitterswijk M, Lee WC, Rademakers R, Boylan KB, Dickson DW, Petrucelli L (2013) Antisense transcripts of the expanded C9ORF72 hexanucleotide repeat form nuclear RNA foci and undergo repeat-associated non-ATG translation in C9FTD/ALS. Acta Neuropathol 126:829-844. https://doi.org/10. 1007/s00401-013-1192-8

6. Mizielinska S, Lashley T, Norona FE, Clayton EL, Ridler CE, Fratta P, Isaacs AM (2013) C9orf72 frontotemporal lobar degeneration is characterised by frequent neuronal sense and antisense RNA foci. Acta Neuropathol 126: 845-857. https://doi.org/10.1007/s00401-013-1200-z

7. Ash PEA, Bieniek KF, Gendron TF, Caulfield T, Lin WL, DeJesusHernandez M, Van Blitterswijk MM, Jansen-West K, Paul JW, Rademakers R, Boylan KB, Dickson DW, Petrucelli L (2013) Unconventional translation of C9ORF72 GGGGCC expansion generates insoluble polypeptides specific to C9FTD/ALS. Neuron 77:639-646. https://doi.org/10.1016/j. neuron.2013.02.004

8. Mori K, Weng S, Arzberger T, May S, Rentzsch K, Broeckhoven C, Van HC, Edbauer D (2013) The C9orf72 GGGGCC Repeat Is Translated into Aggregating Dipeptide-Repeat Proteins in FTLD/ALS. Science 339:1335-1339
9. Zu T, Liu Y, Bañez-Coronel M, Reid T, Pletnikova O, Lewis J, Miller TM, Harms MB, Falchook AE, Subramony SH, Ostrow LW, Rothstein JD, Troncoso JC, Ranum LPW (2013) RAN proteins and RNA foci from antisense transcripts in C9ORF72 ALS and frontotemporal dementia. Proc Natl Acad Sci U S A 110. https://doi.org/10.1073/pnas.1315438110

10. Mizielinska S, Grönke S, Niccoli T, Ridler CE, Clayton EL, Devoy A, Moens T, Norona FE, Woollacott IOC, Pietrzyk J, Cleverley K, Nicoll AJ, Pickering-brown S, Dols J, Cabecinha M, Hendrich O, Fratta P, Fisher EMC, Partridge L, Isaacs AM (2014) C9orf72 repeat expansions cause neurodegeneration in Drosophila through arginine-rich proteins. Science 345:1192-1194

11. Tran H, Almeida S, Moore J, Gendron TF, Chalasani UD, Lu Y, Du X, Nickerson JA, Petrucelli L, Weng Z, Gao FB (2015) Differential toxicity of nuclear RNA foci versus dipeptide repeat proteins in a Drosophila model of C9ORF72 FTD/ALS. Neuron 87:1207-1214. https://doi.org/10.1016/j.neuron. 2015.09.015

12. Everett CM, Wood NW (2004) Trinucleotide repeats and neurodegenerative disease. Brain 127:2385-2405. https://doi.org/10.1093/brain/awh278

13. Saberi S, Stauffer JE, Jiang J, Garcia SD, Taylor AE, Schulte D, Ohkubo T, Schloffman CL, Maldonado M, Baughn M, Rodriguez MJ, Pizzo D, Cleveland D, Ravits J (2018) Sense-encoded poly-GR dipeptide repeat proteins correlate to neurodegeneration and uniquely co-localize with TDP-43 in dendrites of repeat-expanded C9orf72 amyotrophic lateral sclerosis. Acta Neuropathol 135:459-474. https://doi.org/10.1007/s00401-017-1793-8

14. Brettschneider J, Del Tredici K, Lee VMY, Trojanowski JQ (2015) Spreading of pathology in neurodegenerative diseases: a focus on human studies. Nat Rev Neurosci 16:109-120. https://doi.org/10.1038/nrn3887

15. Feiler MS, Strobel B, Freischmidt A, Helferich AM, Kappel J, Brewer BM, Li D, Thal DR, Walther P, Ludolph AC, Danzer KM, Weishaupt JH (2015) TDP-43 is intercellularly transmitted across axon terminals. J Cell Biol 211:897-911. https://doi.org/10.1083/jcb.201504057

16. Porta $S, X U Y$, Restrepo CR, Kwong LK, Zhang B, Brown HJ, Lee EB, Trojanowski JQ, Lee VMY (2018) Patient-derived frontotemporal lobar degeneration brain extracts induce formation and spreading of TDP43 pathology in vivo. Nat Commun 9. https://doi.org/10.1038/s41467018-06548-9

17. Chang YJ, Jeng US, Chiang YL, Hwang IS, Chen YR (2016) The glycinealanine dipeptide repeat from $\mathrm{C} 9$ or $\mathrm{f7} 2$ hexanucleotide expansions forms toxic amyloids possessing cell-to-cell transmission properties. J Biol Chem 291:4903-4911. https://doi.org/10.1074/jbc.M1 15.694273

18. Westergard $T$, Jensen BK, Wen $X$, Cai J, Kropf E, lacovitti L, Pasinelli P, Trotti D (2016) Cell-to-cell transmission of dipeptide repeat proteins linked to C9orf72-ALS/FTD. Cell Rep 17:645-652. https://doi.org/10.1016/ j.celrep.2016.09.032

19. Zhou Q, Lehmer C, Michaelsen M, Mori K, Alterauge D, Baumjohann D, Schludi MH, Greiling J, Farny D, Flatley A, Feederle R, May S, Schreiber F, Arzberger T, Kuhm C, Klopstock T, Hermann A, Haass C, Edbauer D (2017) Antibodies inhibit transmission and aggregation of C9orf72 poly- GA dipeptide repeat proteins. EMBO Mol Med 9:687-702. https://doi.org/10. 15252/emmm.201607054

20. Bass TM, Grandison RC, Wong R, Martinez P, Partridge L, Piper MDW (2007) Optimization of dietary restriction protocols in Drosophila. J Geron - Ser A Biol Sci Med Sci 62:1071-1081. https://doi.org/10.1093/gerona/62.10.1071

21. McGuire SE, Le PT, Osborn AJ, Matsumoto K, Davis RL (2003) Spatiotemporal Rescue of Memory Dysfunction in Drosophila. Science 302:1765-1768. https://doi.org/10.1126/science.1089035

22. Osterwalder T, Yoon KS, White BH, Keshishian H (2001) A conditional tissuespecific transgene expression system using inducible GAL4. Proc Natl Acad Sci U S A 98:12596-12601. https://doi.org/10.1073/pnas.221303298

23. Bischof J, Maeda RK, Hediger M, Karch F, Basler K (2007) An optimized transgenesis system for Drosophila using germ-line-specific $\varphi C 31$ integrases. Proc Natl Acad Sci U S A 104:3312-3317. https://doi.org/10.1073/pnas. 0611511104

24. Mori K, Arzberger T, Grässer FA, Gijselinck I, May S, Rentzsch K, Weng SM, Schludi MH, Van Der Zee J, Cruts M, Van Broeckhoven C, Kremmer E, Kretzschmar HA, Haass C, Edbauer D (2013) Bidirectional transcripts of the expanded C9orf72 hexanucleotide repeat are translated into aggregating dipeptide repeat proteins. Acta Neuropathol 126:881-893. https://doi.org/10. 1007/s00401-013-1189-3

25. Kwon I, Xiang S, Kato M, Wu L, Theodoropoulos P, Wang T, Kim J, Yun J, Xie Y, McKnight SL (2014) Poly-dipeptides encoded by the C9orf72 repeats bind 
nucleoli, impede RNA biogenesis, and kill cells. Science 345:1139-1145. https://doi.org/10.1126/science.1254917

26. Zhang YJ, Guo L, Gonzales PK, Gendron TF, Wu Y, Jansen-West K, O'Raw AD, Pickles SR, Prudencio M, Carlomagno Y, Gachechiladze MA, Ludwig C, Tian R, Chew J, DeTure M, Lin WL, Tong J, Daughrity LM, Yue M, Song Y, Andersen JW, Castanedes-Casey M, Kurti A, Datta A, Antognetti G, McCampbell A, Rademakers R, Oskarsson B, Dickson DW, Kampmann M, Ward ME, Fryer JD, Link CD, Shorter J, Petrucelli L (2019) Heterochromatin anomalies and double-stranded RNA accumulation underlie C9orf72 poly(PR) toxicity. Science 363. https://doi.org/10.1126/science.aav2606

27. Babcock DT, Ganetzky B (2015) Transcellular spreading of huntingtin aggregates in the Drosophila brain. Proc Natl Acad Sci U S A 112: E5427-E5433. https://doi.org/10.1073/pnas.1516217112

28. Kreher SA, Kwon JY, Carlson JR (2005) The molecular basis of odor coding in the Drosophila larva. Neuron 46:445-456. https://doi.org/10.1016/j.neuron. 2005.04.007

29. Zhang YQ, Rodesch CK, Broadie K (2002) Living synaptic vesicle marker: Synaptotagmin-GFP. Genesis 34:142-145. https:/doi.org/10.1002/gene.10144

30. Kanekura K, Yagi T, Cammack AJ, Mahadevan J, Kuroda M, Harms MB, Miller TM, Urano F (2016) Poly-dipeptides encoded by the C9ORF72 repeats block global protein translation. Hum Mol Genet 25:1803-1813. https://doi.org/10. 1093/hmg/ddw052

31. Saiz-Baggetto S, Méndez E, Quilis I, Igual JC, Bañó MC (2017) Chimeric proteins tagged with specific $3 \times \mathrm{HA}$ cassettes may present instability and functional problems. PLoS One 12:1-12. https://doi.org/10.1371/journal. pone. 0183067

32. Solomon DA, Stepto A, Au WH, Adachi $Y$, Diaper DC, Hall R, Rekhi A, Boudi A, Tziortzouda P, Lee YB, Smith B, Bridi JC, Spinelli G, Dearlove J, Humphrey DM, Gallo JM, Troakes C, Fanto M, Soller M, Rogelj B, Parsons RB, Shaw CE, Hortobágyi T, Hirth F (2018) A feedback loop between dipeptide-repeat protein, TDP-43 and karyopherin-a mediates C9orf72-related neurodegeneration. Brain 141:2908-2924. https://doi.org/ 10.1093/brain/awy241

33. Sowade RF, Jahn TR (2017) Seed-induced acceleration of amyloid - $\beta$ mediated neurotoxicity in vivo. Nat Commun 8:1-12. https://doi.org/10. 1038/s41467-017-00579-4

34. Albertson R, Tan V, Leads RR, Reyes M, Sullivan W, Casper-Lindley C (2013) Mapping Wolbachia distributions in the adult Drosophila brain. Cell Microbiol 15:1527-1544. https://doi.org/10.1111/cmi.12136

35. Niccoli T, Partridge L, Isaacs AM (2017) Ageing as a risk factor for ALS/FTD. Hum Mol Genet 26:R105-R113. https://doi.org/10.1093/hmg/ddx247

36. Brettschneider J, Del Tredici K, Irwin DJ, Grossman M, Robinson JL, Toledo JB, Fang L, Van Deerlin VM, Ludolph AC, Lee VMY, Braak H, Trojanowski JQ (2014) Sequential distribution of PTDP-43 pathology in behavioral variant frontotemporal dementia (bvFTD). Acta Neuropathol 127:423-439. https:/ doi.org/10.1007/s00401-013-1238-y

37. Brettschneider J, Del Tredici K, Toledo JB, Robinson JL, Irwin DJ, Grossman M, Suh E, Van Deerlin VM, Wood EM, Baek Y, Kwong L, Lee EB, Elman L, McCluskey L, Fang L, Feldengut S, Ludolph AC, Lee VMY, Braak H, Trojanowski JQ (2013) Stages of pTDP-43 pathology in amyotrophic lateral sclerosis. Ann Neurol 74:20-38. https://doi.org/10.1002/ana.23937

38. Moens TG, Niccoli T, Wilson KM, Atilano ML, Birsa N, Gittings LM, Holbling BV, Dyson MC, Thoeng A, Neeves J, Glaria I, Yu L, Bussmann J, Storkebaum E, Pardo M, Choudhary JS, Fratta P, Partridge L, Isaacs AM (2019) C9orf72 arginine-rich dipeptide proteins interact with ribosomal proteins in vivo to induce a toxic translational arrest that is rescued by elF1A. Acta Neuropathol 137:487-500. https://doi.org/10.1007/s00401-018-1946-4

39. Zhang YJ, Gendron TF, Ebbert MTW, O'Raw AD, Yue M, Jansen-West K, Zhang X, Prudencio M, Chew J, Cook CN, Daughrity LM, Tong J, Song Y, Pickles SR, Castanedes-Casey M, Kurti A, Rademakers R, Oskarsson B, Dickson DW, Hu W, Gitler AD, Fryer JD, Petrucelli L (2018) Poly(GR) impairs protein translation and stress granule dynamics in C9orf72-associated frontotemporal dementia and amyotrophic lateral sclerosis. Nat Med 24: 1136-1142. https://doi.org/10.1038/s41591-018-0071-1

40. Freibaum BD, Lu Y, Lopez-Gonzalez R, Kim NC, Almeida S, Lee KH, Badders N, Valentine M, Miller BL, Wong PC, Petrucelli L, Kim HJ, Gao FB, Taylor JP (2015) GGGGCC repeat expansion in C9orf72 compromises nucleocytoplasmic transport. Nature 525:129-133. https://doi.org/10. 1038/nature14974

41. Jovičič A, Mertens J, Boeynaems S, Bogaert E, Chai N, Yamada SB, Paul JW, Sun S, Herdy JR, Bieri G, Kramer NJ, Gage FH, Van Den Bosch L, Robberecht
W, Gitler AD (2015) Modifiers of C9orf72 dipeptide repeat toxicity connect nucleocytoplasmic transport defects to FTD/ALS. Nat Neurosci 18:12261229. https://doi.org/10.1038/nn.4085

42. Zhang K, Donnelly CJ, Haeusler AR, Grima JC, Machamer JB, Steinwald P, Daley EL, Miller SJ, Cunningham KM, Vidensky S, Gupta S, Thomas MA, Hong I, Chiu SL, Huganir RL, Ostrow LW, Matunis MJ, Wang J, Sattler R, Lloyd TE, Rothstein JD (2015) The C9orf72 repeat expansion disrupts nucleocytoplasmic transport. Nature 525:56-61. https://doi.org/10.1038/ nature 14973

43. Conlon EG, Lu L, Sharma A, Yamazaki T, Tang T, Shneider NA, Manley JL (2016) The C9ORF72 GGGGCC expansion forms RNA G-quadruplex inclusions and sequesters hnRNP $\mathrm{H}$ to disrupt splicing in ALS brains. Elife 5: 1-28. https://doi.org/10.7554/eLife.17820

44. Cooper-Knock J, Walsh MJ, Higginbottom A, Highley JR, Dickman MJ, Edbauer D, Ince PG, Wharton SB, Wilson SA, Kirby J, Hautbergue GM, Shaw PJ (2014) Sequestration of multiple RNA recognition motif-containing proteins by C9orf72 repeat expansions. Brain 137:2040-2051. https://doi.org/ 10.1093/brain/awu120

45. Lee YB, Chen HJ, Peres JN, Gomez-Deza J, Attig J, Štalekar M, Troakes C, Nishimura AL, Scotter EL, Vance C, Adachi Y, Sardone V, Miller JW, Smith BN, Gallo JM, Ule J, Hirth F, Rogelj B, Houart C, Shaw CE (2013) Hexanucleotide repeats in ALS/FTD form length-dependent RNA foci, sequester RNA binding proteins, and are neurotoxic. Cell Rep 5:1178-1186. https://doi.org/ 10.1016/j.celrep.2013.10.049

46. Tao Z, Wang H, Xia Q, Li K, Li K, Jiang X, Xu G, Wang G, Ying Z (2015) Nucleolar stress and impaired stress granule formation contribute to C9orf72 RAN translation-induced cytotoxicity. Hum Mol Genet 24:24262441. https://doi.org/10.1093/hmg/ddv005

47. Guo Q, Lehmer C, Martínez-Sánchez A, Rudack T, Beck F, Hartmann H, Pérez-Berlanga M, Frottin F, Hipp MS, Hartl FU, Edbauer D, Baumeister W, Fernández-Busnadiego R (2018) In situ structure of neuronal C9orf72 polyGA aggregates reveals proteasome recruitment. Cell 172:696-705.e12. https://doi.org/10.1016/j.cell.2017.12.030

48. Zhang YJ, Gendron TF, Grima JC, Sasaguri H, Jansen-West K, Xu YF, Katzman RB, Gass J, Murray ME, Shinohara M, Lin WL, Garrett A, Stankowski JN, Daughrity L, Tong J, Perkerson EA, Yue M, Chew J, Castanedes-Casey M, Kurti A, Wang ZS, Liesinger AM, Baker JD, Jiang J, Lagier-Tourenne C, Edbauer D, Cleveland DW, Rademakers R, Boylan KB, Bu G, Link CD, Dickey CA, Rothstein JD, Dickson DW, Fryer JD, Petrucelli L (2016) C9ORF72 poly(GA) aggregates sequester and impair HR23 and nucleocytoplasmic transport proteins. Nat Neurosci 19:668-677. https:// doi.org/10.1038/nn.4272

49. Lee JG, Takahama S, Zhang G, Tomarev SI, Ye Y (2016) Unconventional secretion of misfolded proteins promotes adaptation to proteasome dysfunction in mammalian cells. Nat Cell Biol 18:765-776. https://doi.org/10. 1038/ncb3372

50. Lasagna-Reeves CA, Castillo-Carranza DL, Sengupta U, Guerrero-Munoz MJ, Kiritoshi T, Neugebauer V, Jackson GR, Kayed R (2012) Alzheimer brainderived tau oligomers propagate pathology from endogenous tau. Sci Rep 2. https://doi.org/10.1038/srep00700

51. Khosravi B, Hartmann H, May S, Möhl C, Ederle H, Michaelsen M, Schludi MH, Dormann D, Edbauer D (2017) Cytoplasmic poly-GA aggregates impair nuclear import of TDP-43 in C9orf72 ALS/FTLD. Hum Mol Genet 26:790-800 https://doi.org/10.1093/hmg/ddw432

52. Nonaka T, Masuda-Suzukake M, Hosokawa M, Shimozawa A, Hirai S, Okado H, Hasegawa M (2018) C9ORF72 dipeptide repeat poly-GA inclusions promote intracellular aggregation of phosphorylated TDP-43. Hum Mol Genet 27:2658-2670. https://doi.org/10.1093/hmg/ddy174

53. Baborie A, Griffiths TD, Jaros E, Perry R, McKeith IG, Burn DJ, MasudaSuzukake M, Hasegawa M, Rollinson S, Pickering-Brown S, Robinson AC, Davidson YS, Mann DMA (2015) Accumulation of dipeptide repeat proteins predates that of TDP-43 in frontotemporal lobar degeneration associated with hexanucleotide repeat expansions in C9ORF72 gene. Neuropathol Appl Neurobiol 41:601-612. https://doi.org/10.1111/nan.12178

54. Proudfoot M, Gutowski NJ, Edbauer D, Hilton DA, Stephens M, Rankin J, Mackenzie IRA (2014) Early dipeptide repeat pathology in a frontotemporal dementia kindred with C9ORF72 mutation and intellectual disability. Acta Neuropathol 127:451-458. https://doi.org/10.1007/s00401-014-1245-7

55. Vatsavayai SC, Yoon SJ, Gardner RC, Gendron TF, Vargas JNS, Trujillo A, Pribadi M, Phillips JJ, Gaus SE, Hixson JD, Garcia PA, Rabinovici GD, Coppola G, Geschwind DH, Petrucelli L, Miller BL, Seeley WW (2016) Timing and 
significance of pathological features in C9orf72 expansion-associated frontotemporal dementia. Brain 139:3202-3216. https://doi.org/10.1093/ brain/aww250

56. Ding $X$, Ma M, Teng J, Teng RKF, Zhou S, Yin J, Fonkem E, Huang JH, Wu E, Wang X (2015) Exposure to ALS-FTD-CSF generates TDP-43 aggregates in glioblastoma cells through exosomes and TNTs-like structure. Oncotarget 6: 24178-24191. https://doi.org/10.18632/oncotarget.4680

57. Asai H, Ikezu S, Tsunoda S, Medalla M, Luebke J, Haydar T, Wolozin B, Butovsky O, Kügler S, Ikezu T (2015) Depletion of microglia and inhibition of exosome synthesis halt tau propagation. Nat Neurosci 18:1584-1593. https://doi.org/10.1038/nn.4132

58. Mackenzie IRA, Frick P, Grässer FA, Gendron TF, Petrucelli L, Cashman NR, Edbauer D, Kremmer E, Prudlo J, Troost D, Neumann M (2015) Quantitative analysis and clinico-pathological correlations of different dipeptide repeat protein pathologies in C9ORF72 mutation carriers. Acta Neuropathol 130: 845-861. https://doi.org/10.1007/s00401-015-1476-2

59. van Blitterswijk M, DeJesus-Hernandez M, Niemantsverdriet E, Murray ME, Heckman MG, Diehl NN, Brown PH, Baker MC, Finch NCA, Bauer PO, Serrano G, Beach TG, Josephs KA, Knopman DS, Petersen RC, Boeve BF, GraffRadford NR, Boylan KB, Petrucelli L, Dickson DW, Rademakers R (2013) Association between repeat sizes and clinical and pathological characteristics in carriers of C9ORF72 repeat expansions (Xpansize-72): a cross-sectional cohort study. Lancet Neurol 12:978-988. https://doi.org/10. 1016/S1474-4422(13)70210-2

60. Fournier $\mathrm{C}$, Barbier M, Camuzat A, Anquetil V, Lattante S, Clot F, Cazeneuve C, Rinaldi D, Couratier P, Deramecourt V, Sabatelli M, Belliard S, Vercelletto $M$, Forlani S, Jornea L, Brice A, Auriacombe S, Blanc F, Bouteleau-Bretonnière C, Ceccaldi M, Didic M, Dubois B, Duyckaerts C, Etcharry-Bouix F, Golfier V, Hannequin D, Lacomblez L, Le Ber I, Levy R, Michel BF, Pasquier F, ThomasAnterion C, Pariente J, Sellal F, Benchetrit E, Bertin H, Bertrand A, Bissery A, Bombois S, Boncoeur MP, Cassagnaud P, Chastan M, Chen Y, Chupin M, Colliot O, Delbeuca X, Delmaire C, Gerardin E, Hossein-Foucher C, Habert MO, Lautrette G, Lebouvier T, Lehéricy S, Le Toullec B, Martineau K, Mackowiak MA, Monteil J, Petyt G, Pradat PF, Oya AH, Rollin-Sillaire A, Salachas F, Sayah S, Wallon D, Leguern E (2019) Relations between C9orf72 expansion size in blood, age at onset, age at collection and transmission across generations in patients and presymptomatic carriers. Neurobiol Aging 74:234.e1-234.e8. https://doi.org/10.1016/j.neurobiolaging.2018.09.010

61. Giiselinck I, Van Mossevelde S, Van Der Zee J, Sieben A, Engelborghs S, De Bleecker J, Ivanoiu A, Deryck O, Edbauer D, Zhang M, Heeman B, Bäumer V, Van Den Broeck M, Mattheijssens M, Peeters K, Rogaeva E, De Jonghe P, Cras P, Martin JJ, De Deyn PP, Cruts M, Van Broeckhoven C (2016) The C9orf72 repeat size correlates with onset age of disease, DNA methylation and transcriptional downregulation of the promoter. Mol Psychiatry 21: 1112-1124. https://doi.org/10.1038/mp.2015.159

62. Wegmann S, Bennett RE, Delorme L, Robbins AB, Hu M, McKenzie D, Kirk MJ, Schiantarelli J, Tunio N, Amaral AC, Fan Z, Nicholls S, Hudry E, Hyman BT (2019) Experimental evidence for the age dependence of tau protein spread in the brain. Sci Adv 5. https://doi.org/10.1126/sciadv.aaw6404

\section{Publisher's Note}

Springer Nature remains neutral with regard to jurisdictional claims in published maps and institutional affiliations.

Ready to submit your research? Choose BMC and benefit from:

- fast, convenient online submission

- thorough peer review by experienced researchers in your field

- rapid publication on acceptance

- support for research data, including large and complex data types

- gold Open Access which fosters wider collaboration and increased citations

- maximum visibility for your research: over $100 \mathrm{M}$ website views per year

At BMC, research is always in progress.

Learn more biomedcentral.com/submissions 